\title{
Effect of various treatment and glazing (coating) techniques on the roughness and wettability of ceramic dental restorative surfaces
}

\author{
G. Aksoy ${ }^{\mathrm{a}}, \mathrm{H}$. Polat ${ }^{\mathrm{b}, *}$, M. Polat ${ }^{\mathrm{c}}, \mathrm{G} \cdot$ Coskun $^{\mathrm{a}}$ \\ a School of Dentistry, Agean University, Bornova, Izmir, Turkey \\ ${ }^{\mathrm{b}}$ Department of Chemistry, İzmir Institute of Technology, Urla, Izmir, Turkey \\ ${ }^{\mathrm{c}}$ Department of Chemical Engineering, Izmir Institute of Technology, Urla, İzmir, Turkey
}

Received 29 August 2006; received in revised form 14 September 2006; accepted 15 September 2006

Available online 27 September 2006

\begin{abstract}
Surface treatment procedures such as grinding and polishing are needed to provide the ceramic dental restorative materials with proper fitting and occlusion. The treated surfaces are customarily glazed to improve the strength and smoothness. Though smoothness and wetting of the dental surfaces are important to minimize bacterial plaque retention, influence of the surface treatment and glazing procedures on the final surface roughness and its correlation to wettability are overlooked.

In this work, effect of various treatment (diamond fraising, stoning, sanding and aluminum oxide and rubber polishing) and glazing (auto and overglazing) techniques on the final roughness and the resulting wettability of dental ceramic surfaces were investigated using scanning electron microscopy (SEM) observations and atomic force microscopy (AFM) scans, 75 scans per sample. The surfaces were characterized and assigned an average roughness measure, $R_{\mathrm{a}}$. The wettability of the same surfaces was evaluated using micro-contact angle measurements ( 25 micro-bubbles placed on a grid on each surface) to correlate the final surface roughness and wettability.

The results show that overglazing prevails over surface irregularities from different treatment procedures and provides homegeneously smooth surfaces with mean $R_{\mathrm{a}}<10 \mathrm{~nm}$. It also produces uniformly wetted surfaces with low contact angles around $20^{\circ}$. The autoglazed surfaces are less smooth (mean $R_{\mathrm{a}}$ around $50 \mathrm{~nm}$ ) and displays sporadic topographic irregularities. They display larger and less uniform contact angles ranging between $35^{\circ}$ and $50^{\circ}$. The results suggest that overglazing should be preferred after surface treatment to obtain a smooth and well-wetted dental ceramic surface.
\end{abstract}

(C) 2006 Elsevier B.V. All rights reserved.

Keywords: Surface treatment; Glazing; Roughness; Contact angle; Wetting; Wettability

\section{Introduction}

Ceramics have been traditionally preferred as a dental restorative material because of their aesthetic quality and excellent biocompatibility. Their ability to yield relatively smooth surfaces, which minimizes plaque deposition and tissue inflammation, is another important reason for their preference in dental applications. Therefore, the degree of surface roughness of dental ceramics and its effect on biocompatibility have been widely studied [1-9]. Surface roughness also determines the degree of abrasion caused by one tooth on another. Since

\footnotetext{
* Corresponding author. Tel.: +90 232750 7531; fax: +90 2327507509 .

E-mail addresses: hurriyetpolat@iyte.edu.tr, hpolat2005@yahoo.com (H. Polat).
}

ceramics are usually harder materials than natural tooth, if they are not treated to smoothness, their abrasive effects will create series of problems in the oral environment [10].

In the cooling stage of the fired ceramic, some micro-cracks develop on the ceramics surface, increasing the surface roughness and decreasing the strength of material due to stresses accumulating within the crack sites. These factors reduce the performance of the ceramic restorative materials in oral environment [11-14]. Moreover, the dental ceramic surfaces should be treated to desired shape after forming to improve aesthetical quality and occlusion using fraising with a diamond tip. Unfortunately, application of a diamond fraise creates micro-cracks and rough regions on the ceramic surface [15]. Most of the time, diamond fraising is assisted with additional treatments such as stoning, sanding, aluminum oxide or rubber polishing to reduce the surface roughness. However, these additional surface treatments 
alone may not be sufficient to provide a smooth enough surface [16-19]. Owen glazing of the ceramic surfaces is commonly practiced to address these problems. The glaze layer fills the micro-cracks and forms a hard surface layer. It strengthens the dental restorative, decreases its exposure to outside environment and provides the necessary smoothness [15,20-24]. Therefore, the properties expected from a ceramic restorative material are determined to a great degree by the successful application of the glaze layer [25-27].

Two glazing techniques, namely autoglazing and overglazing (glass overcoating) are commonly employed in dental applications. In autoglazing, the surface of the ceramic itself is allowed to melt at high temperatures (around $940^{\circ} \mathrm{C}$ ) to provide the glaze layer. In overglazing, a thin layer of low-fusing glass overcoat is spread over the ceramic surface and fired at a lower temperature (around $650-700^{\circ} \mathrm{C}$ ) to obtain the glaze layer.

The relative merits of the various treatment procedures and the type of subsequent glazing on the final roughness of the surface are still subject to discussion [15,26,28-34]. Moreover, wettability of the final dental surface and its relation to the surface roughness has not been considered in detail. Though wettability is an intrinsic material property from a thermodynamical perspective, the roughness of the surface would mechanically affect wettability, hence, plaque retention.

The purpose of this study was to investigate the effect of various surface treatment and glazing techniques on the final surface quality of the restorative dental porcelains. Scanning electron microscopy (SEM) and atomic force microscopy (AFM) have been employed to quantitatively determine the surface roughness using multiple scans and statistical analysis. The mean wettability and wettability distribution of the same surfaces, obtained through micro-contact angle measurements using multiple micron-size droplets on a surface-grid, were employed to correlate the final roughness of the surface and its wettability.

\section{Materials and methods}

\subsection{Casting of the ceramic samples}

A commercial ceramic powder which is widely practiced for metal framework ceramic applications (Ceramco-II from Ceramco Inc., NJ, USA) was chosen to prepare the ceramic green bodies in this study. A mold containing 6 cylindrical holes of $10 \mathrm{~mm}$ in diameter and $5 \mathrm{~mm}$ in height was built for casting the ceramic samples. A 1-mm-thick layer of Remanium CS ${ }^{\circledR}$ metallic alloy (from Dentaurum, Ispringen, Germany) was positioned at the base of each cylindrical hole to act as a foundation for the subsequent ceramic layer. The ceramic paste was cast over the metal layer until it filled the mold completely to a perfectly level surface. This gave a top surface which measured about $0.79 \mathrm{~cm}^{2}$. The samples were removed from the mold after a setting time of about $10 \mathrm{~min}$ and fired. The vacuum firing was carried out in a vacuum furnace Model Vita Vakumat 40T (Vita-zahn fabrik AG bad Sackingen, Germany) which operated at 0.038 atm in two steps based on the manufacturer's directions; holding the samples for $9 \mathrm{~min}$ at $920^{\circ} \mathrm{C}$ and for $7 \mathrm{~min}$ at $910^{\circ} \mathrm{C}$.

\subsection{Surface treatment and glazing of the ceramic samples}

The six ceramic samples from the firing of a single casting batch were subjected to the same surface treatment procedure. Then, a new set of six samples were cast and fired for another surface treatment procedure. The process was repeated for the five treatment procedures which are presented in Table 1 along with the abbreviations used to represent them throughout the text, resulting in a total number of 30 ceramic samples.

The samples whose surfaces were treated by one of the procedures in Table 1 were subjected to ultrasonic treatment in double distilled water to remove any surface residues, dried and analyzed using scanning electron microscopy (SEM) and atomic force microscopy (AFM). The ultrasonic bath used was CEIACP102 model with a working frequency of $55 \mathrm{~Hz}$.

The details about the SEM and AFM work are presented in the next section. Following the SEM and AFM analyses, the treated samples were re-cleaned in an ultrasonic bath and dried. The six samples from any one of the treatment procedures were divided into two groups and either autoglazing or overglazing was applied to each group. In autoglazing, the samples were directly placed in the furnace, preheated at $621^{\circ} \mathrm{C}$ for $3 \mathrm{~min}$, heated to $918^{\circ} \mathrm{C}$ using a temperature ramp of $83^{\circ} \mathrm{C} / \mathrm{min}$ and kept at this temperature for $0.5 \mathrm{~min}$. In overglazing, a layer of ceramco overglaze liquid was applied to the surfaces and a monolayer of glass particles from the same manufacturer was deposited on each sample. The samples were placed in the furnace and dried

Table 1

Surface treatment procedures applied to the ceramic samples, their brief descriptions and abbreviations used in their representations

\begin{tabular}{|c|c|}
\hline Procedure & Explanation \\
\hline Diamond fraising (DF) & $\begin{array}{l}\text { The surfaces were treated by a fine, precision diamond fraise operated at } \\
25,000 \mathrm{rpm} \text { (from Ivoclar Vivadent AG, Schaan, Liechtenstein) }\end{array}$ \\
\hline Diamond fraising + stoning $(\mathrm{DF}+\mathrm{S})$ & $\begin{array}{l}\text { The surfaces were treated with a stone head (from Sho Dental Corp, Menlo Park, } \\
\text { California, USA) at 25,000 rpm following diamond fraising }\end{array}$ \\
\hline Diamond + fraising + stoning + rubber polishing $(D F+S+R)$ & $\begin{array}{l}\text { The surfaces were polished with a rubber head (from Dedeco Dental \& } \\
\text { Development and Mfg. Corp., New York, USA) at 25,000 rpm following diamond } \\
\text { fraising and stoning }\end{array}$ \\
\hline Diamond fraising + stoning + aluminum oxide polishing $(\mathrm{DF}+\mathrm{S}+\mathrm{AO})$ & $\begin{array}{l}\text { The surfaces were polished with } 0.1 \mu \mathrm{m} \text { aluminum oxide powder (from Hunter } \\
\text { Association, New Jersey, USA) following diamond fraising and stoning }\end{array}$ \\
\hline Diamond fraising + stoning + sanding $(\mathrm{DF}+\mathrm{S}+\mathrm{SP})$ & $\begin{array}{l}\text { The surfaces were sanded using a fine grit precision sand paper (from EC Moore } \\
\text { Co, Michigan, USA) following diamond fraising and stoning }\end{array}$ \\
\hline
\end{tabular}


for $3 \mathrm{~min}$ at $64{ }^{\circ} \mathrm{C}$. The furnace temperature was then increased to $871^{\circ} \mathrm{C}$ using a temperature ramp of $56^{\circ} \mathrm{C} / \mathrm{min}$ and were kept $0.5 \mathrm{~min}$ at this temperature. Both the autoglazed and overglazed samples were cooled to room temperature under ambient pressure, cleaned in an ultrasonic bath to remove any surface residues and dried. The samples were analyzed using SEM, AFM and contact angle observations.

\subsection{SEM and AFM studies}

As outlined in the preceding section, SEM and AFM analyses were carried out on the surfaces of the ceramic samples before and after glazing. The SEM (Philips XL 30SFG) was utilized to obtain representative pictures of the surfaces at $2500 \times$ magnification. In the AFM scans (Digital Instruments MMAFM-2/1700EXL), the contact mode was used first to obtain a topographic 'picture' over $100 \mu \mathrm{m} \times 100 \mu \mathrm{m}$ randomly selected areas on the surface. Built-in statistical analysis tools of the AFM were used to obtain an average roughness value, $R_{\mathrm{a}}$, of each scanned area. The $R_{\mathrm{a}}$ value is the arithmetic average of the height of peaks and depth of valleys from a mean line expressed in nanometers. A pane of nearly smooth window glass, for example, has a $R_{\mathrm{a}}$ value of about $100 \mathrm{~nm}$. The number of scans were 60 (6 samples times 10 scans per sample) for the treated surfaces and 30 for the glazed surfaces ( 3 samples times 10 scans per sample). Therefore, statistical means could be employed to obtain a mean $R_{\mathrm{a}}$ value and the deviation around this mean. The SEM results are included for illustration purposes and no roughness analysis is reported for the SEM pictures.

\subsection{Contact angle measurements}

Contact angle is the angle at the three-point contact at a solid-liquid-gas interface and gives a measure of the wettability of the solid by the liquid. A smaller contact angle means a more wettable, hydrophilic ceramic surface, which means that the dental material prefers to be wetted by water and is less receptive to hydrophobic organic residues. Though it is an intrinsic thermodynamical property of the solid, mechanical factors such as roughness directly influence the angle at the three-point contact.

In this study, contact angles were measured in ceramic/air/ water system with a goniometer/microscope setup (Krüss GmbH, Germany model G10) using a modified sessile drop method suggested by Polat and Chander [35] (Fig. 1). The ceramic surface was divided into a $5 \times 5$ grid for contact angle measurement and a micro-droplet of double-distilled water (about $400 \mu \mathrm{m}$ in diameter) was generated with a micrometer syringe and placed on a specific potion of the grid using a micro-positioning device and a micrometer-driven micropipette. The angle which developed at the three point air/water/ceramic interface was measured using a microscope-goniometer system for the droplet. The process was repeated for each grid point to obtain 25 measurements for each sample. This yielded 150 readings for each surface treatment procedure (6 samples times 25 readings per sample) and 75 readings for each glazing technique (3 samples times 25 readings per sample). Similar to the AFM

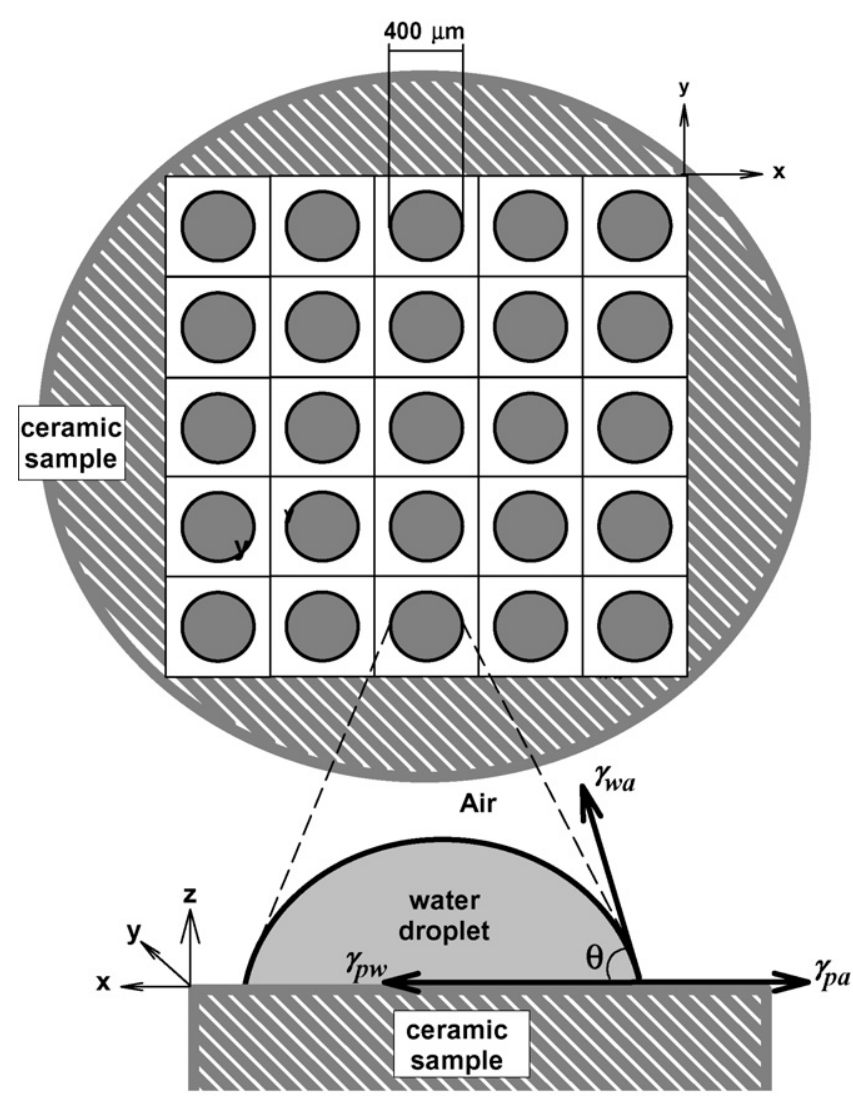

Fig. 1. A schematic view of modified micro-contact angle measurements using sessile drops. $\gamma_{\mathrm{pw}}, \gamma_{\mathrm{pa}}$ and $\gamma_{\mathrm{wa}}$ are respective ceramic-water, ceramic-air and water-air interfacial tensions. The upper figure is drawn for illustration purposes and is not to the scale.

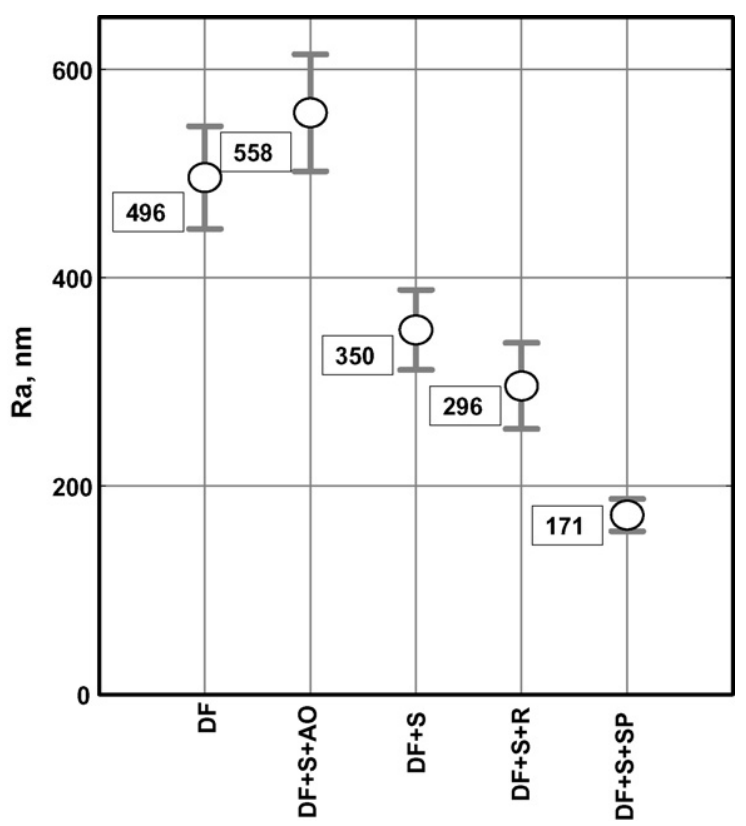

Fig. 2. Mean surface roughness $\left(R_{\mathrm{a}}\right)$ values (circles) along with 2-standard deviation spread around the means (error bars) for the ceramic surfaces subjected to different surface finishing procedures. Each symbol represents the mean $R_{\mathrm{a}}$ value for 60 AFM scans. 
scans, statistical tools could be used to obtain a mean contact angle and spread around this mean using the large number of readings. The mean contact angle gives an average wettability for the surface but is not sufficient for proper representation since two quite different surfaces can have the same mean contact angle. The spread around this mean aids evaluation of contact angle readings since it provides valuable information regarding surface heterogeneities.

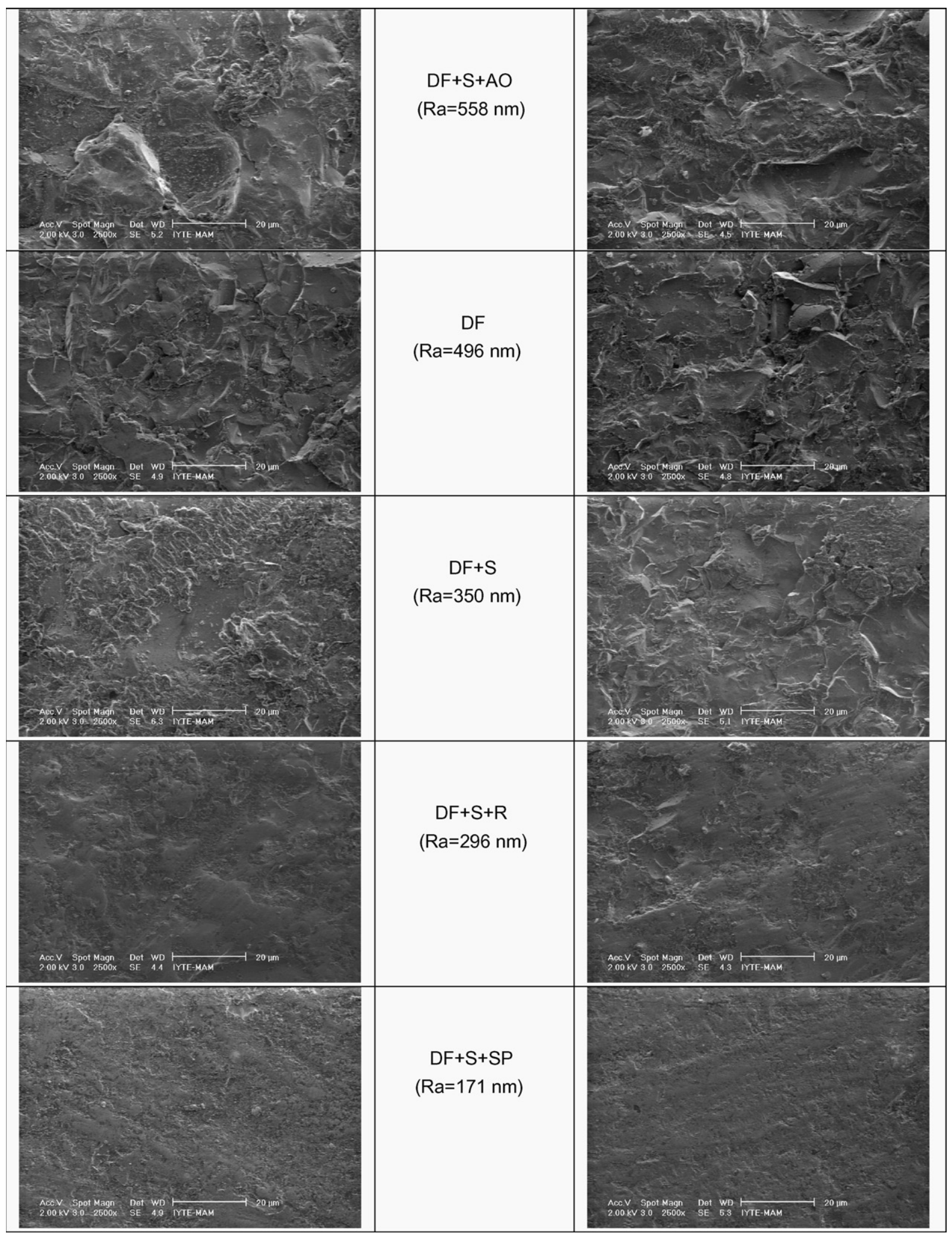

Fig. 3. Selected SEM pictures of the finished dental ceramic surfaces prior to glazing. 


\section{Results}

\subsection{Effect of surface treatment and glazing on final surface roughness}

The mean $R_{\mathrm{a}}$ values from the AFM scans for each surface treated by one of the procedures given in Table 1 are presented in Fig. 2. Since the AFM scans were repeated on six identical samples for each treatment procedure and 10 scans were obtained on each sample surface, each circle in the figure represents the mean $R_{\mathrm{a}}$ for 60 independent scans. The figure also includes the error bars covering a 2-standard deviation spread generated by sigma plot statistical analysis and plotting software (Jandel Scientific, CA, USA).

The figure demonstrates that various surface treatment procedures generate surfaces with quite different degrees of roughness. The average surface roughness measure, $R_{\mathrm{a}}$, decreases from $558 \mathrm{~nm}$ for $\mathrm{DF}+\mathrm{S}+\mathrm{AO}$ case to $171 \mathrm{~nm}$ for $\mathrm{DF}+\mathrm{S}+\mathrm{SP}$ case. The 2-standard deviation spreads around this mean show that there is also a large variability in surface roughness. The SEM analysis illustrate that this variability could be considered 'uniformly distributed' due to random rifts and valleys on the surface. Some selected SEM pictures are presented in Fig. 3 to emphasize this point.

The mean $R_{\mathrm{a}}$ values obtained from the AFM scans for the autoglazed and overglazed surfaces are presented in Fig. 4 along with the data for the treated surfaces previously given in Fig. 2 for comparison. Similarly, these plots also include the 2-standard deviation spread around the mean $R_{\mathrm{a}}$ values. The statistical analyses are based on 60 scans for the treated surfaces and 30 scans for the glazed surfaces. It is apparently clear that application of both glazing techniques reduces the surface roughness signifi-

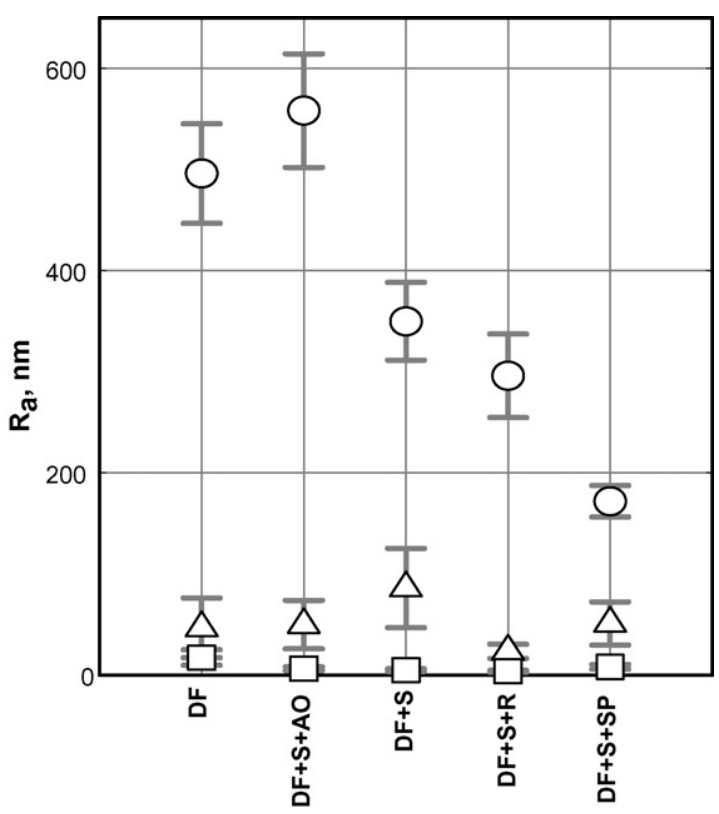

Fig. 4. Mean surface roughness $\left(R_{\mathrm{a}}\right)$ values for finished (circles), auto glazed (triangles) and over glazed (squares) surfaces along with 2-standard deviation spread around the mean values (error bars). Each symbol represents the mean $R_{\mathrm{a}}$ value of $60 \mathrm{AFM}$ scans for surface treatments and $30 \mathrm{AFM}$ scans for glazing. cantly irrespective of the previous surface treatment procedure applied. However, overglazing produces quite homogeneous surfaces with much lower mean roughness $\left(R_{\mathrm{a}}<10 \mathrm{~nm}\right)$ and extremely small spread. Any differences originally present on the surface due to different surface treatment procedures are completely eradicated upon overglazing. Similar observations were also made for autoglazing though this technique produces rougher surfaces compared to overglazing $\left(R_{\mathrm{a}}\right.$ around $\left.50 \mathrm{~nm}\right)$ and the spread around the mean $R_{\mathrm{a}}$ values are also larger. The SEM observations showed that the higher mean $R_{\mathrm{a}}$ values and the larger spread of the autoglazed surfaces were due to sporadically distributed surface defects which look like micron-sized craters.

\subsection{Effect of surface treatment and glazing on wettability}

The contact angles measured on the glazed surfaces are presented in Fig. 5. The symbols in the figure give the mean contact angles for 75 readings along with the error bars for 2-standard deviation spread around this mean. It is immediately clear that the surfaces with an overglaze layer show a low mean contact angle of about $20^{\circ}$ with minimal spread around the mean. This means that overglazed surfaces are quite homogeneous. Since the AFM scans showed a nearly perfectly smooth surface for overglazed surfaces, the measured contact angle value of $20^{\circ}$ can be considered the "real" measure of the wettability of the overglazed surfaces. Such a low value means a hydrophilic and easily wettable surface.

In the case of autoglazed surfaces, the mean contact angles are larger and vary between $30^{\circ}$ and $55^{\circ}$ for depending on the treatment applied to the surface. Also, the surfaces are much less homogeneous as can be seen from the wider error bars. This behavior is most probably due to the sporadic irregularities observed on the autoglazed surfaces in the SEM pictures and

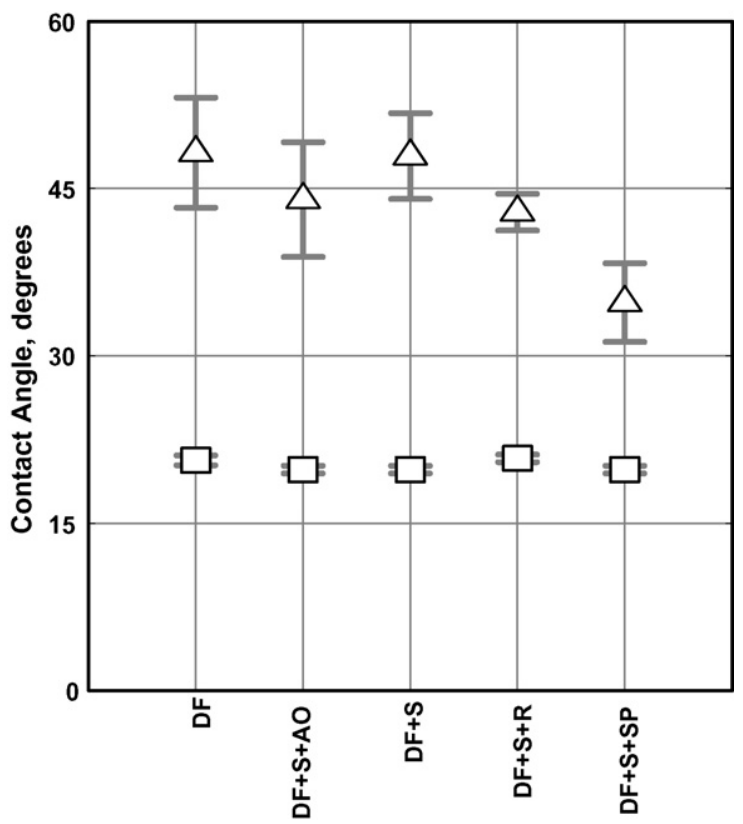

Fig. 5. Contact angles for autoglazed (triangles) and overglazed (squares) surfaces. Each symbol represents a mean contact angle for 75 readings with corresponding 2-standard deviations spreads around the means. 


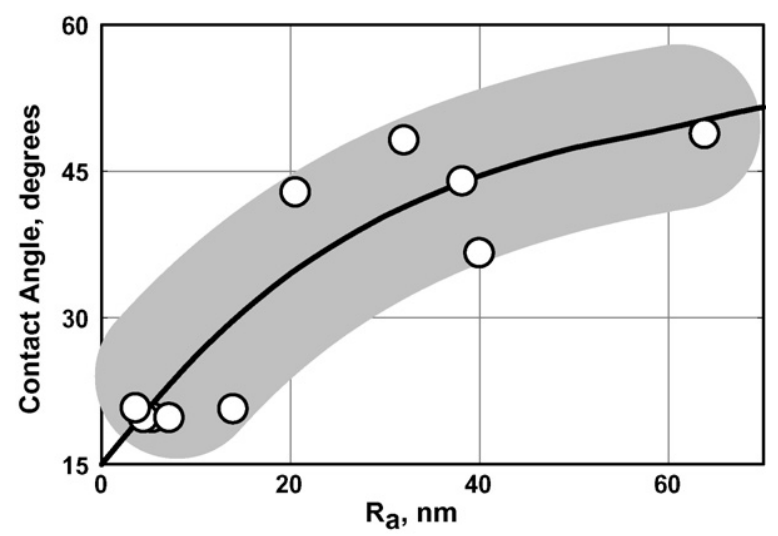

Fig. 6. Curvilinear correlation between the mean surface roughness $\left(R_{\mathrm{a}}\right)$ and mean contact angles. Each symbol corresponds to 30 AFM scans and 75 contact angle readings.

AFM scans rather than a variation on the surface composition of the ceramic surface.

In Fig. 6, the mean contact angles measured in this work for all the glazed surfaces are plotted as a function of the mean $R_{\mathrm{a}}$ values of these surfaces. A curvilinear correlation analysis results in a correlation coefficient of 0.786 which can be considered quite significant. The figure shows the curvilinear correlation curve (solid line) with 0.786 confidence interval (gray region). The significant correlation observed suggests that the roughness of the surface determines the wettability of the ceramic dental restorative materials. This would in turn directly determine the degree of plaque retention on the surface and should be taken seriously when choosing a proper treatment or glazing technique.

\section{Discussion}

In this study, the effect of various surface treatment procedures and glazing techniques on the final roughness and wettability of ceramic dental restorative materials was investigated using scanning electron microscopy, atomic force microscopy and contact angle measurements.

It was observed that the roughness of the ceramic surface was high and varied significantly for different surface treatment procedures. In this work, diamond fraising followed by stoning and sanding gave the lowest surface roughness with a mean $R_{\mathrm{a}}$ value of $171 \mathrm{~nm}$.

Glazing decreased the surface roughness significantly irrespective of the prior surface treatment applied. The autoglazed surfaces generated rougher surfaces (mean $R_{\mathrm{a}}$ of $50 \mathrm{~nm}$ ) with significant deviations around the mean due to sporadic topographic irregularities. The mean $R_{\mathrm{a}}$ values for the overglazed surfaces were below $10 \mathrm{~nm}$ and the surfaces were quite homogeneous with extremely small deviations from the mean $R_{\mathrm{a}}$ values.

The mean contact angles for the overglazed surfaces were lower for all cases $\left(20^{\circ}\right)$ and did not show any significant spread.
This suggests overglazing produces a more wettable ceramic surfaces. The autoglazed samples displayed higher and more scattered contact angles, most probably due to the surface irregularities observed in the SEM and AFM work.

\section{Conclusion}

The results conclusively show that any differences with respect to the final smoothness and the wettability of the surface which originate from the use of various treatment procedures are almost completely eradicated by subsequent coating. Overglazing which leads to a smoother and more wettable ceramic surface should be preferred since these properties will discourage plaque retention.

\section{References}

[1] R. Ahmad, S.M. Morgano, B.M. Wu, R.A. Giordano, J. Prosthet. Dent. 94 (5) (2005) 421.

[2] A.R. Curtis, A.J. Wright, G.J.P. Fleming, J. Dent. (2005).

[3] G.J.P. Fleming, L. Nolan, J.J. Harris, J. Dent. 33 (5) (2005) 405.

[4] G.J.P. Fleming, S.F.A. El-Lakwah, J.J. Harris, P.M. Marquis, Dent. Mater. 20 (2) (2004) 142.

[5] L.S. Yin, S. Jahanmir, L.K. Ives, Wear 255 (7-12) (2003) 975.

[6] C.M. Bollen, P. Lambrechts, M. Quirynen, Int. J. Prostoth. 13 (2000) 468.

[7] M. Quirynen, C.M.L. Bollen, J. Clin. Periodont. 22 (1995) 1.

[8] M. Quirynen, M. Macechal, H. Busscher, J. Clin. Periodont. 17 (1990) 138.

[9] M. Kuwata, The Theory and Practice for Ceramo-metal Restorations, Quintescence, Chicago, 1980, p. 100.

[10] K. Kawai, M. Urano, Scanning 23 (2001) 227.

[11] W. Oh, R. DeLong, K.J. Anusavice, J. Prosthet. Dent. 87 (4) (2002) 451

[12] K.J. Anusavice, C. Shen, B. Vermost, Dent. Mater. 8 (1992) 149.

[13] K.J. Anusavice, B. Hojjatie, J. Dent. Res. 70 (1991) 1009.

[14] V. Piddock, A.J. Qualtrough, E. Brough, Int. J. Prostoth. 4 (1991) 132.

[15] M. Albakry, M. Guazzato, M.V. Swain, J. Dent. 32 (2004) 91.

[16] M.T. Ward, W.H. Tate, J.M. Powers, Int. J. Prostoth. 16 (2003) 74.

[17] A.R. Grieve, I.W. Jeffrey, S.J. Sharma, Clin. Oral Invest. 7 (2003) 27.

[18] J. Martinez-Gomis, B.J.M. Anglade, Am. J. Dent. 13 (2000) 35.

[19] G.E. Monarsky, D.F. Taylor, J. Prosthet. Dent. 25 (1971) 299

[20] C.S. Frederick, N. Frankel, R.J. Smales, Int. J. Prostoth. 13 (2000) 66.

[21] H.Y. Chen, R. Hickel, J.C. Setcos, K.H. Kunzelmann, J. Prosthet. Dent. 82 (4) (1999) 468.

[22] J.A. Griggs, J.Y. Thompson, K.J. Anusavice, J. Dent. Res. 75 (1996) 1414.

[23] C.W. Fairhurst, P.E. Lockwood, R.D. Ringle, Dent. Mater. 8 (1992) 203.

[24] R. Giordano, M. Cima, D. Pober, J. Dent. Res. 70 (1991) 433.

[25] M. Guazzato, L. Quach, M. Albakry, M.V. Swain, J. Dent. 33 (1) (2005) 9.

[26] H. Baharav, B.Z. Laufer, A. Mizrachi, H.S. Cardash, J. Prosthet. Dent. 76 (1) (1996) 19.

[27] G.E. Monasky, D.E. Taylor, J. Prosthet. Dent. 25 (1971) 299.

[28] J.A. Griggs, J.V. Thomson, K.J. Anusavice, J. Dent. Res. 75 (1996) 1414.

[29] M.J. Edge, W.C. Wagner, J. Oral Rehabil. 22 (1995) 421.

[30] M.S. Scurria, J.M. Powers, J. Prosthet. Dent. 71 (1994) 174.

[31] D.C. Jagger, A. Harrison, J. Prosthet. Dent. 72 (1994) 320.

[32] C.J.W. Patterson, A.C. McLundie, D.R. Stirrups, J. Prosthet. Dent. 65 (1991) 383.

[33] M. Zarkind, S. Lauer, N. Stern, J. Prosthet. Dent. 55 (1986) 30.

[34] N. Barghi, L. Alexander, R.A. Draughn, J. Prosthet. Dent. 35 (1976) 648.

[35] H. Polat, S. Chander, J. Coll. Surf. A 146 (1999) 199. 